\title{
Antecedents of Attitude Toward SMS Advertising in the UK
}

\author{
Mehran Darabi, Peter Reeves, and Sunil Sahadev
}

\begin{abstract}
A new research report from eMarketer (2014) suggests that firms in the UK were expected to increase their advertising expenditure via mobile phones by $96 \%$, from $£ 1.03$ bn in 2013 to $£ 2.02$ bn in 2014. Considering the growth in SMS advertising expenditure in the UK, it is important to understand the underlying factors forming consumers' attitudes toward text marketing. Founded on Fishbein's (1967) expectancy value theory, it is suggested that attitude towards SMS advertising is the result of consumers' beliefs about such practices. Therefore, this research aims to identify beliefs that form consumers' attitude toward SMS advertising in the UK.

A questionnaire research survey was administered. A seven-point Likert survey instrument (ranging from (1) strongly disagree to (7) strongly agree) was developed using validated scales from previous studies in mobile marketing and advertising. Some of the measuring items were reverse coded to prevent biased responses. Data was collected from UK based university students $(N=236$, Females 103, Males 133) in the form of convenience sampling. The sample frame is justified, as students are heavy users of mobile phone technologies and are knowledgeable about SMS advertisements (Muk and Chung 2014).

The results show that five factors directly influence the consumers' attitude toward SMS advertising in the UK. In order of significance (from most important to least important) they are: entertainment, personalisation, irritativeness, credibility and informativeness. Mediation analysis also found that the more knowledgeable the consumers become about mobile communications, the more likely they are to be entertained by SMS advertising messages, and less likely to find text marketing irritating. Furthermore, incentives can increase the credibility of text marketing messages and reduce the level of their irritativeness. It was also concluded that prior permission is fully mediated via irritativeness in terms of its influence on text marketing attitude. Finally, the study shows that both consumer control and privacy concerns influence SMS advertising attitude via mediating variables of credibility and personalisation.
\end{abstract}

References available upon requests

M. Darabi $(\bowtie) \bullet$ P. Reeves $\bullet$ S. Sahadev

University of Salford, Salford, UK

e-mail: M.Darabi@edu.salford.ac.uk; P.Reeves@salford.ac.uk; S.Sahadev@salford.ac.uk

(C) Academy of Marketing Science 2016

L. Petruzzellis, R.S. Winer (eds.), Rediscovering the Essentiality of Marketing,

Developments in Marketing Science: Proceedings of the Academy of Marketing

Science, DOI 10.1007/978-3-319-29877-1_4 